\title{
Pneumocystis jirovecii Pneumonia in Pediatric Inflammatory Bowel Disease: A Case Report and Literature Review
}

\author{
Sally J. Lawrence ${ }^{1 *}$, Manish Sadarangani ${ }^{2}$ and Kevan Jacobson ${ }^{1}$ \\ 'Department of Pediatric Gastroenterology, Hepatology and Nutrition, BC Children's Hospital, University of British Columbia, \\ Vancouver, BC, Canada, ${ }^{2}$ Vaccine Evaluation Center, BC Children's Hospital Research Institute, University of British \\ Columbia, Vancouver, BC, Canada
}

OPEN ACCESS

Edited by:

Eytan Wine,

University of Alberta, Canada

Reviewed by:

Moftah Hussin Alhagamhmad, University of New South

Wales, Australia

Nikhil Pai,

McMaster University, Canada

Duška Tješić-Drinković,

University of Zagreb, Croatia

*Correspondence:

Sally J. Lawrence sally.lawrence@cw.bc.ca

Specialty section:

This article was submitted to Pediatric Gastroenterology, Hepatology and Nutrition, a section of the journal

Frontiers in Pediatrics

Received: 28 April 2017 Accepted: 06 July 2017

Published: 24 July 2017

Citation:

Lawrence SJ, Sadarangani M and Jacobson K (2017) Pneumocystis jirovecii Pneumonia in Pediatric Inflammatory Bowel Disease: A Case Report and Literature Review. Front. Pediatr. 5:161. doi: 10.3389/fped.2017.00161
Immunosuppressive therapy is a known risk factor for opportunistic infections. We report the first case of severe Pneumocystis jirovecii infection requiring intensive care in a pediatric patient with inflammatory bowel disease (IBD). The literature was reviewed and there were 92 reported cases of Pneumocystis pneumonia (PCP) in patients with IBD. Most sources were case reports and there was likely reporting bias toward patients receiving immunomodulators, anti-tumor necrosis factor (anti-TNF) therapy, and those who died. Overall, $56 \%$ of patients were males and $58 \%$ had Crohn's disease. The median age was 45 years (interquartile range $30-68$, range $8-78$ ) and $86 \%$ of patients were lymphopenic. The case-fatality rate was $23 \%$. Corticosteroids were used as IBD treatment in $88 \%$ of patients who subsequently developed PCP, 42\% received thiopurines, 44\% used antiTNF therapy, and 15\% received either cyclosporine or tacrolimus. Rates of mono, dual, triple, and quadruple immunosuppression therapy were $35,35,29$, and $2 \%$, respectively. This report highlights the importance of considering PCP in immunosuppressed lymphopenic pediatric IBD patients who present with unusual symptoms. Moreover, it should give gastroenterologists the impetus to limit immunosuppressive therapy to its minimal effective dose and consider options such as exclusive enteral nutrition wherever possible. Although there is no place for global PCP prophylaxis in IBD given the low incidence, in an era when there is increasing use of biologic agents with combination immunosuppressive therapy, the risk-benefit profile of PCP chemoprophylaxis should be revisited in selected cohorts such as patients on triple immunosuppression with corticosteroids, thiopurines, and a biological agent or calcineurin inhibitor, especially in lymphopenic individuals.

Keywords: Pneumocystis jirovecii, pneumocystis pneumonia, inflammatory bowel disease, pediatric, opportunistic infection, immunosuppressive therapy, lymphopenia

\section{INTRODUCTION}

Immunosuppressive therapy is a known risk factor for opportunistic infections (1). We report a case that highlights the importance of considering opportunistic infection in immunosuppressed pediatric patients with inflammatory bowel disease (IBD) who present with unusual symptoms. We present the first case of severe Pneumocystis jirovecii (P. jirovecii) infection requiring intensive care in a pediatric patient with IBD. 


\section{CASE REPORT}

A 12-year-old Caucasian girl was diagnosed with gastric and ileocolonic Crohn's disease (CD), Paris classification L3, L4a, B1, G1, having presented with growth failure and abdominal pain and having undergone endoscopic and magnetic resonance enterography assessment. She failed exclusive enteral nutrition (EEN) and was treated with oral prednisone tapered over 3 months with maintenance azathioprine (AZA) $(2 \mathrm{mg} / \mathrm{kg} /$ day). Treatment resulted in resolution of clinical symptoms and improved biochemical markers. She had recurrence of symptoms after 9 months with abdominal pain and diarrhea. Infective work-up was negative and she was commenced on oral budesonide $9 \mathrm{mg}$ and her AZA dose was increased $(2.5 \mathrm{mg} / \mathrm{kg} /$ day $)$. Thiopurine metabolites at this stage were normal [6-TGN $278 \mathrm{pmol} / 8 \times 10^{8}$ (normal range 230-400), 6-MMPN $734 \mathrm{pmol} / 8 \times 10^{8}$ (normal range <5,700)].

Three months later, she presented with a 3-day history of fever, dry cough, and progressive dyspnea. On examination, she was hypoxic with $\mathrm{SaO}_{2} 90 \%$ despite 15 1/min high flow oxygen. She had severe lymphopenia $\left(0.0 \times 10^{9} / 1\right.$ on manual count), elevated white cell count $\left(10.8 \times 10^{9} / 1\right)$, raised C-reactive protein $(268 \mathrm{mg} / \mathrm{l})$, and lactate dehydrogenase was $763 \mathrm{U} / \mathrm{l}$. Chest X-ray showed bilateral interstitial infiltrates (Figure 1). She required intensive care for bi-level positive airway pressure respiratory support. AZA and budesonide were discontinued and she was commenced on piperacillin-tazobactam, clarithromycin, and oseltamivir to provide empiric coverage against bacteria (including atypical) and influenza, with minimal improvement in symptoms. An induced sputum sample was negative for bacterial and viral pathogens [culture and broad panel polymerase chain reaction (PCR)] but revealed $P$. jirovecii on silver stain (Figure 2). Intravenous (IV) trimethoprim-sulfamethoxazole (TMP-SMX) $20 \mathrm{mg} / \mathrm{kg} \mathrm{TMP} / 100 \mathrm{mg} / \mathrm{kg}$ SMX and methylprednisone $1 \mathrm{mg} / \mathrm{kg}$ twice daily were initiated, which resulted in improvement in respiratory status and weaning of respiratory support over 7 days.

Prior to discharge, she was investigated for an underlying primary immunodeficiency. Human immunodeficiency (HIV)

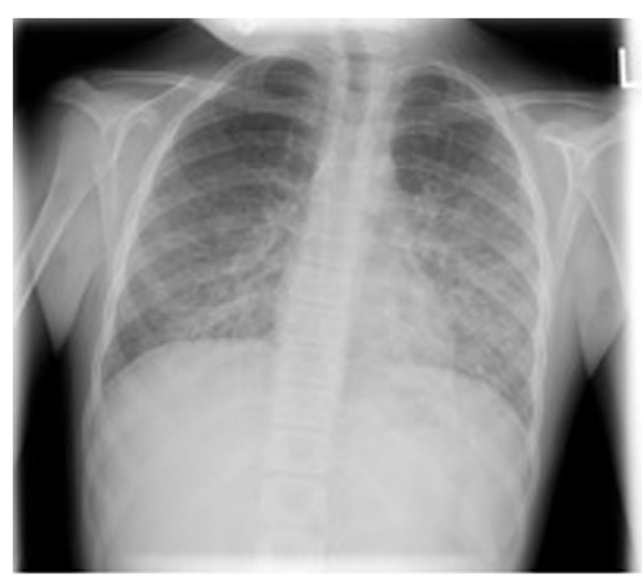

FIGURE 1 | Chest X-ray demonstrating bilateral pulmonary infiltrates caused by pneumocystis pneumonia. testing was negative and immunoglobulin levels were normal. $\mathrm{B}$ and $\mathrm{T}$ cell panel revealed a low absolute count of CD3, CD4, and $\operatorname{CD} 8\left(0.47,0.36,0.14 \times 10^{9} / 1\right.$ respectively) with normal number of B cells $\left(0.43 \times 10^{9} / 1\right)$, normal CD4/CD8 ratio (2.43), and a good response to previous diphtheria and tetanus vaccines. She remained lymphopenic during admission, but this slowly improved. Notably, at IBD diagnosis, she had normal lymphocyte levels [lymphocyte count 1.7-2.6 (normal range $0.9-3.5 \times 10^{9} / 1$ )]; however, after AZA initiation, she had intermittent lymphopenia $\left(0.4-1.2 \times 10^{9} / 1\right)$. Thiopurine methyltransferase activity testing was unfortunately unavailable at diagnosis.

She was discharged on oral TMP-SMX for 21 days, having had 3 days of IV therapy. She received 3 days of methylprednisone followed by 5 days of oral prednisone, which was tapered over 2.5 months. AZA was restarted at a reduced dose $(1.5 \mathrm{mg} / \mathrm{kg} /$ day $)$. Within 2 months, she had normal lymphocyte numbers with a normal absolute CD4 count $\left(0.56 \times 10^{9} / 1\right)$ and normal T-cell numbers. She developed an urticarial rash thought to be secondary to TMP-SMX 4 days post discharge and was changed to oral clindamycin and primaquine to complete the 21-day treatment course. She was then started on prophylactic oral dapsone, which was discontinued when she developed arthralgia. She has not subsequently taken PCP prophylaxis.

One year post-PCP admission, she was commenced on adalimumab monotherapy due to ongoing poor growth, abdominal pain, and an elevated fecal calprotectin $(>1,800 \mu \mathrm{g} / \mathrm{g})$. This resulted in resolution of symptoms, catch-up growth, and progression through puberty. She has had no further significant infections in the last 5 years and her lymphocyte count has remained stable.

\section{LITERATURE REVIEW AND DISCUSSION}

\section{Overview of $P$. jirovecii Pneumonia}

Pneumocystis jirovecii (formerly known as Pneumocystis carinii) is a ubiquitous opportunistic fungus, which causes

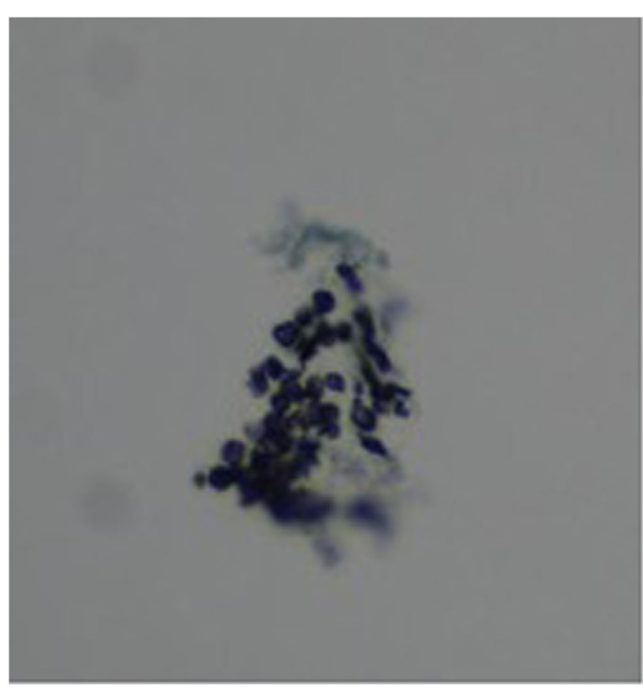

FIGURE 2 | Grocott-Gomori's methenamine silver stain of sputum specimen showing "cup shaped" Pneumocystis jirovecii cysts in small aggregates. 
pneumonia [Pneumocystis pneumonia (PCP)]. It was first described in 1940s malnourished infants (2). In the 1980s, it was associated with HIV-infected patients with low CD4 counts (3). PCP continues to be an acquired immune deficiency syndrome-defining illness although the advent of antiretroviral therapy has resulted in incidence reduction (4). PCP has been recognized as a disease in children with primary cellmediated immunodeficiency, patients receiving chemotherapy for hematological malignancies, solid organ, and bone marrow transplant recipients and in patients requiring immunosuppressants (5). Notably, the incidence in the immunosuppressed non-HIV population is increasing with the escalating use of immunosuppressive agents $(4,6,7)$. Inflammatory autoimmune conditions such as IBD account for up to $20 \%$ of PCP in HIV-negative patients (8).

Pneumocystis jirovecii exposure appears to occur early in life and is often asymptomatic $(9,10)$. Reinfection of the immunosuppressed host through environmental or person-to-person transmission rather than reactivation from latency appears to be the major mode of acquisition in immunosuppressed patients (10). Effective host defenses against $P$. jirovecii are mediated by the innate, T-cell, and to a lesser extent, humoral immune responses. In immunosuppressed patients, the infection results in a dysfunctional immune response, composed of mononuclear cells, CD8 lymphocytes, and activated macrophages, which causes diffuse lung damage (11). Moreover, the inhaled Pneumocystis trophozoites inhibit epithelial repair processes within the alveoli resulting in severe lung damage (12).

Adult data show that unlike in HIV-infected individuals where presentation can be slow and insidious, non-HIV infected immunocompromised individuals can have an aggressive course often culminating in respiratory failure over several days (4, 13-15). PCP is characterized by a non-productive cough, fever, and dyspnea. On chest X-ray, diffuse bilateral interstitial pulmonary infiltrates are most common (4). In equivocal cases, high resolution chest computed tomography is more sensitive and commonly shows diffuse ground glass opacity (16).

Pneumocystis jirovecii cannot be cultured, therefore, definitive diagnosis is made by visualization of the organism's cysts and trophozoites. This can be achieved using induced sputum, bronchioalveolar lavage specimens, or lung tissue stained with Grocott-Gomori's methenamine silver or visualized using immunofluorescence. Unfortunately, sensitivity is $<67 \%$ in the non-HIV infected patient due to low numbers of $P$. jirovecii (17). PCR testing of $P$. jirovecii nucleic acid in respiratory samples is more sensitive for diagnosis; however, discrimination between colonization and actual disease has been challenging. Quantitative PCR is thought to help differentiate between these two entities better than qualitative PCR with recent research focusing on oral washes as a less invasive diagnostic tool $(18,19)$.

First line treatment of PCP is IV TMP-SMX (15-20 mg/kg/ $24 \mathrm{~h}$ of the trimethoprim component in three divided doses) due to excellent tissue penetration, rapid response, and low cost (4). Adverse reactions include leukopenia, thrombocytopenia, and rashes including Stevens-Johnson syndrome (5). However, reactions appear less common in children (20). Alternative therapy includes clindamycin plus primaquine, pentamidine, and dapsone (21). Atovaquone has been used for mild disease as it is less effective than TMP-SMX, but better tolerated (22). Corticosteroids have been used as an adjuvant treatment in severe disease, reducing respiratory failure and the length of intensive care unit stay (23).

PCP mortality rates are between 20 and $60 \%$ in immunocompromised non-HIV infected individuals in contrast to rates of $10-20 \%$ in HIV-infected patients $(4,7,13,15,24,25)$. The more severe course is thought to be secondary to a more disseminated pulmonary inflammatory response and diagnostic delay $(4,26)$.

\section{PCP and IBD}

A retrospective cohort study determined that IBD patients were at an elevated risk of PCP compared to the general population with an increased relative risk (hazard ratio 2.96; 95\% CI $1.75-4.29)$ but low absolute risk (0.03\%) (26). The incidence of PCP in immunosuppressed IBD patients [thiopurines, methotrexate, calcineurin inhibitors, anti-tumor necrosis factor (anti-TNF) agents, or steroids] was $32 / 100,000$ patient-years (PY) compared to 5.5/100,000 PY for non-immunosuppressed IBD patients (26). The risk appeared greater in CD compared with ulcerative colitis (UC) (26). In another population-based IBD cohort, double immunosuppression resulted in a higher risk of PCP than monotherapy (0.6/100 vs. $0.3 / 100$ PY). There were few patients on triple therapy making risk analysis challenging (27).

There is only one published case of a child with IBD developing PCP. The 8-year-old CD patient, on infliximab monotherapy, developed PCP with concurrent disseminated histoplasmosis after 15 months therapy. His disease course was not severe. He did not require respiratory support and responded to TMP-SMX. He was maintained on budesonide with no PCP prophylaxis (28). PCP has been described in adult IBD patients on corticosteroids, calcineurin inhibitors, thiopurines, and antiTNF agents $(8,26,29-33)$.

We performed a literature review of PCP in IBD. A database search for studies on MEDLINE, EMBASE, and the Cochrane Controlled Trials Registry was performed. References of included articles were searched for further studies. Table 1 summarizes the details of published IBD studies reporting patients with PCP. Most sources were case reports [evidence level 5 (34)], and there was likely reporting bias toward immunomodulators, anti-TNF therapy, and patients who died. There were 92 reported cases of PCP in patients with IBD in the English literature, of which 56\% were males and 58\% had CD. The median age was 45 years [interquartile range (IQR) 30-68, range 8 -78]. There was little documented information about CD4 counts at PCP diagnosis; however, $86 \%$ (12/14) of patients were lymphopenic. The case-fatality rate (CFR) was $23 \%$ $(7 / 31)$ based on the reported outcome data. Where medication was documented, rates of mono, dual, triple, and quadruple immunosuppression therapy were 35\% (18/52), 35\% (18/52), $29 \%(15 / 52)$, and $2 \%(1 / 52)$, respectively. The numbers were too small to comment on the effect of incremental risk with increasing numbers of immunosuppressants. Corticosteroids, as mono, dual or triple therapy, were used as IBD treatment, in $88 \%(46 / 52)$ of patients who developed PCP. $42 \%(22 / 52)$ 
TABLE 1 | Summary of published literature of inflammatory bowel disease patients who developed pneumocystis pneumonia $(n=92)$.

\begin{tabular}{|c|c|c|c|c|c|c|c|}
\hline Reference & $\begin{array}{c}\text { No of } \\
\text { patients }\end{array}$ & $\begin{array}{l}\text { Disease } \\
\text { subtype }\end{array}$ & Gender & Age (years) & Medication at time of PJP & $\begin{array}{l}\text { Single (S), dual (D), triple } \\
\text { (TR), quadruple (Q) } \\
\text { immunosuppression }\end{array}$ & Outcome \\
\hline Khatchatourian and Seaton (30) & 1 & UC & M & 68 & $\mathrm{CS}+\mathrm{T}$ & $\mathrm{D}$ & Died \\
\hline Lee et al. (35) & 1 & UC & M & 21 & $\mathrm{CS}+\mathrm{T}$ & $\mathrm{D}$ & Survived \\
\hline Takenaka et al. (36) & 3 & UC (100\%) & $F(67 \%)$ & $26-68$ & $\begin{array}{l}\mathrm{CS}+\mathrm{T}(67 \%) \\
\mathrm{CS}(33 \%)\end{array}$ & $\begin{array}{l}S(33 \%) \\
D(67 \%)\end{array}$ & Survived (100\%) \\
\hline Bernstein et al. (29) & 2 & UC (100\%) & $M(100 \%)$ & $32-73$ & CS (100\%) & S (100\%) & Died (50\%) \\
\hline Escher et al. (32) & 2 & UC (100\%) & $M(100 \%)$ & $72-74$ & $\begin{array}{l}\mathrm{CS}+\mathrm{Tac} \\
\mathrm{CS}+\mathrm{Tac}+\mathrm{T}\end{array}$ & $\begin{array}{l}\mathrm{D}(50 \%) \\
\operatorname{TR}(50 \%)\end{array}$ & Died (100\%) \\
\hline Art et al. (37) ${ }^{\mathrm{a}}$ & 3 & UC (100\%) & M & 32 & $C S+C S A+T(100 \%)$ & TR (100\%) & Died (33\%) \\
\hline Quan et al. (38) & 1 & UC & M & 63 & $\mathrm{CS}+\mathrm{CSA}$ & $\mathrm{D}$ & Died \\
\hline Scott et al. (31) & 1 & UC & M & 43 & $\mathrm{CS}+\mathrm{CSA}$ & $\mathrm{D}$ & Survived \\
\hline Smith and Hanauer (39) & 1 & UC & M & 32 & $\mathrm{CS}+\mathrm{CSA}$ & $\mathrm{D}$ & Survived \\
\hline Desales et al. (8) & 1 & CD & M & 36 & $\mathrm{CS}+\mathrm{T}+$ anti-TNF & TR & Survived \\
\hline Lawrance et al. (40) & 2 & CD (100\%) & $F(50 \%)$ & $18-32$ & $\begin{array}{l}\mathrm{CS}+\mathrm{T}+\text { anti-TNF, } \\
\mathrm{CS}+\mathrm{MTX}+\mathrm{MMF}+\text { anti-TNF}\end{array}$ & $\begin{array}{l}\text { TR }(50 \%) \\
\text { Q (50\%) }\end{array}$ & Survived (100\%) \\
\hline Cotter et al. (27) & 3 & UC (67\%) & $M(100 \%)$ & $63-78$ & $\begin{array}{l}\mathrm{MTX}+\text { anti-TNF} \\
\mathrm{CS}+\text { anti-TNF} \\
\mathrm{T}\end{array}$ & $\begin{array}{l}S(33 \%) \\
D(67 \%)\end{array}$ & Survived (100\%) \\
\hline Tschudy and Michail (28) & 1 & CD & M & 8 & Anti-TNF & $S$ & Survived \\
\hline Iwama et al. (41) & 1 & $C D$ & M & 51 & Anti-TNF & $S$ & Survived \\
\hline Velayos and Sandborn (42) & 1 & CD & $\mathrm{M}$ & 19 & $\mathrm{~T}+$ anti-TNF & $D$ & Survived \\
\hline Kaur and Mahl (43) & 1 & CD & $\mathrm{M}$ & 59 & $\mathrm{CS}+$ anti-TNF & D & Died \\
\hline Stratakos et al. (44) & 1 & CD & $\mathrm{F}$ & 77 & $\mathrm{CS}+$ anti-TNF & $\mathrm{D}$ & Survived \\
\hline Estrada et al. (45) & 1 & UC & M & 45 & $\mathrm{CS}+\mathrm{T}+$ anti-TNF & TR & Survived \\
\hline Sharma and Rao (46) & 1 & CD & $\mathrm{F}$ & 36 & $\mathrm{CS}+\mathrm{T}+$ anti-TNF & TR & Survived \\
\hline Seddik et al. (47) & 1 & CD & M & 29 & $\mathrm{CS}+\mathrm{T}+$ anti-TNF & TR & Survived \\
\hline Itaba et al. (48) & 1 & CD & $\mathrm{F}$ & 57 & $\mathrm{CS}+\mathrm{T}+$ anti-TNF & TR & Survived \\
\hline DeFilippis et al. (49) & 1 & $C D$ & $\mathrm{~F}$ & 56 & $\mathrm{CS}+\mathrm{MTX}+$ anti-TNF & TR & Survived \\
\hline Long et al. (26) & 38 & $\begin{array}{l}\text { CD (55\%) } \\
\text { UC (40\%) }\end{array}$ & $F(55 \%)$ & $\begin{array}{c}43-57 \\
\text { IQR }\end{array}$ & $\begin{array}{l}\text { CS: } 11 / 38 \\
\text { T: } 1 / 38 \\
T+C S: 5 / 38 \\
\text { CS + 2IM: } 2 / 38 \\
\text { CS + IM + anti-TNF: 2/38 }\end{array}$ & $\begin{array}{c}\text { S: } 12 / 38(32 \%) \\
\text { D: } 5 / 38(13.2 \%) \\
\text { TR: } 4 / 38(10.5 \%)\end{array}$ & ND \\
\hline Kaur and Mahl (33) & 16 & CD $(88 \%)$ & ND & ND & Anti-TNF (100\%) & ND & ND \\
\hline Fillatre et al. (14) & 1 & ND & ND & ND & ND & ND & ND \\
\hline Bienvenu et al. (7) & 4 & ND & ND & ND & ND & ND & ND \\
\hline Roblot et al. (50) & 2 & ND & ND & ND & ND & ND & ND \\
\hline
\end{tabular}

CS, corticosteroids; T, thiopurines (azathioprine/6-Mercaptopurine); Tac, tacrolimus; CSA, cyclosporine; anti-TNF, anti-tumor necrosis factor therapy (adalimumab or infliximab); MTX, methotrexate; MMF, mycophenolate mofetil; IMs, immunomodulators (thiopurine, tacrolimus); ND, not documented; CD, Crohn's disease; UC, ulcerative colitis; IQR, interquartile range.

${ }^{a}$ Data on gender and age only available for the one patient who died.

received thiopurines, $44 \%(23 / 52)$ took anti-TNF therapy, and $15 \%(8 / 52)$ used either cyclosporine or tacrolimus.

\section{PCP and Corticosteroids}

Corticosteroids are known to reduce CD4 lymphocytes, which predisposes to PCP development (51). Corticosteroids have emerged as a major contributor to PCP in the non-HIV immunosuppressed population and the risk is particularly increased at or above $16 \mathrm{mg}$ of prednisolone (50-52). The median therapy duration prior to PCP was 8-12 weeks $(50,51)$. Interestingly, in some studies, the disease only became apparent when corticosteroids were tapered $(24,50,51)$.

\section{PCP and Thiopurines}

Thiopurines (AZA and 6-mercaptopurine) can inhibit cellmediated immunity, which influences PCP development. In the literature, two IBD patients on thiopurine monotherapy developed PCP, 10 were on dual therapy, as was the case with our patient, and 10 were on triple therapy. The CFR in this group was $19 \%(3 / 16)$, where outcome data were available.

\section{PCP and Calcineurin Inhibitors}

Cyclosporine works by inhibiting production of IL-2 by helper T-cells and by affecting T-cell, B-cell, neutrophil, and mast cell function. In the literature, 50\% (4/8) of IBD patients with PCP died $(32,37,38)$. Such cases have prompted a discussion regarding the role of prophylactic antibiotics in patients on cyclosporine; however, the limited cases and reporting bias needs to be considered $(37,53,54)$.

\section{PCP and Methotrexate}

Three patients in the IBD literature developed PCP while on methotrexate in combination with corticosteroid and anti-TNF therapy. Methotrexate has been implicated in the development of PCP in rheumatoid arthritis with 28 documented cases, $25 \%$ of whom died $(55,56)$. 


\section{PCP and Anti-TNF Agents}

Cytokines inhibited by anti-TNF agents are involved in the host response to PCP resulting in reduced PCP clearance. Moreover, anti-TNF therapy can lower CD4 counts making patients more susceptible to PCP (57). Review of the Food and Drug Administration Adverse Event Reporting System data between 1998 and 2003 identified 84 patients with PCP associated with infliximab, with a mean age of 55 years; $19 \%$ of patients had IBD. Concomitant immunosuppressive agents included immunomodulators (66\%), corticosteroids (50\%), and cyclosporine (5\%). The CFR was $27 \%$ (33). PCP has been reported to occur 9-14 weeks after the first infliximab induction dose $(33,57,58)$. Notably, Colombel et al. did not report any cases of PCP associated with 3,160 patients (in six global clinical trials) on adalimumab (59). However, there are two case reports of PCP in IBD patients on adalimumab $(8,40)$. In total, 162 cases of PCP are reported in the IBD and rheumatology literature associated with anti-TNF therapy, which includes pediatric patients. Of the 138 patients with outcome information available, $20 \%$ died. Unfortunately, studies do not always specify whether single, double, or triple immunosuppression was used $(8,26-28,33$, $40-49,56,58,60,61)$. Data on the incidence of PCP in patients on anti-TNF agents are largely based on rheumatoid arthritis studies and most are population based. The majority of studies report incidence rates $<50$ cases per 100,000 PY (62). Results are hampered by heterogeneity in the method of PCP diagnosis, moreover, discrimination between $P$. jirovecii colonization and actual disease can be challenging.

There are no published data on PCP associated with vedolizumab, ustekinumab, or other novel IBD treatments $(63,64)$. More long-term data are required to assess safety profiles of these agents.

\section{Other Risk Factors for PCP in Non-HIV Infected Immunosuppressed Patients}

The use of multiple immunosuppressive agents incrementally increases the risk of opportunistic infection in IBD; moreover, malnutrition and surgery can play a role, although this has not been specifically addressed in PCP $(1,27,40,51,52,62)$. As documented in our case, lymphopenia (especially CD4 count $<300$ cells $/ \mathrm{mm}^{3}$ ) has been associated with increased risk of PCP in $60-95 \%$ of cases $(5,24,50,65)$. Notably, not all immunosuppressed patients will present with lymphopenia $(24,65)$.

Long et al. reviewed a case series of 38 IBD patients who developed PCP and showed that rates of hospitalization at some stage within 60 days of PCP were high (50\%) (26). Moreover, patients had higher rates of comorbidities, principally, lung disease and diabetes mellitus, compared to the background population. Advanced age $>65$ years was found to be an additional risk (26).

\section{PCP in Other Pediatric Non-HIV Immunosuppressive Conditions}

A population-based cohort study in juvenile idiopathic arthritis patients reported an incidence of 7/100,000 PY (66). Multiple immunosuppressive agents and lymphopenia are important risk factors in rheumatic diseases (67). The risk of PCP in pediatric cancer depends on the malignancy type and chemotherapy category. Lymphoid malignancies have the highest risk with rates of $22-45 \%$ (68). The overall risk of PCP post solid organ transplant has been estimated to be $5-15 \%$ in the absence of PCP prophylaxis (5). Risk factors include malnutrition, previous cytomegalovirus infection, and underlying lung disease. Medications such as steroids, antilymphocyte agents, calcineurin inhibitors, and biological agents such as alemtuzumab (antiCD52 monoclonal antibody) have also been implicated (5).

\section{Prophylaxis against PCP}

In a 2012 survey of PCP prophylaxis practice by gastroenterologists, $11 \%$ prescribed prophylaxis to their patients with IBD on combination therapy. Gastroenterologists were more likely to prescribe if they had previous practical experience of PCP, or practiced in an academic center (69).

The effects of PCP can be severe, however, prevention entails using drugs with adverse effects that may counterbalance the benefits, as occurred in our patient. The guidelines for PCP prophylaxis in $\mathrm{HIV}$-infected patients have been universally adopted, but there is a lack of consensus on prophylaxis with TMP-SMX in IBD patients. A recent Cochrane meta-analysis of prophylactic treatment with TMP-SMX in non-HIV infected patients included 1,412 patients, of which 520 were children. The authors were unable to find published literature addressing prophylaxis in IBD. In patients with hematological cancers and transplant recipients, they reported an $85 \%$ reduction in PCP incidence with prophylaxis and PCP-related mortality reduced by $83 \%$ with few adverse events reported (20). No children in the included studies had a severe adverse event compared to $3.1 \%$ of adults suggesting a lower probability of harm in children.

There is insufficient evidence to recommend PCP prophylaxis for all IBD patients on immunosuppressive monotherapy; however, with increasing number of immunosuppressive agents, the risk of opportunistic infection is known to increase $(1,27,62)$. Large studies addressing the specific incremental increased risk associated with multiple immunosuppressive agents especially triple therapy have not been done. This needs to be considered, as the use of multiple immunosuppressive agents are increasing. A recent study showed that approximately half of patients started on anti-TNF therapy were already on two immunosuppressive agents (40). Dietary therapies (EEN, partial enteral nutrition, and exclusion diets) in CD are increasingly being used and investigated and are attractive options to limit immunosuppression and improve nutrition in this population (70-72).

A study using simulation modeling to address cost and comparative effectiveness of PCP prophylaxis in CD concluded that at the present incidence, routine chemoprophylaxis was not cost effective but, based on limited data, it may be effective in triple immunosuppressive therapy (73). The 2014 European Crohn's and Colitis opportunistic infection guidelines recommend PCP prophylaxis in IBD patients on triple immunosuppression including either a calcineurin inhibitor or anti-TNF therapy. This recommendation is based on expert gastroenterology and infectious disease opinion (74). Other practical approaches proposed for patients on high-dose steroids and multiple immunosuppressants include measurement 
of CD4 counts in those patients with a total lymphocyte count of $<600$ cells $/ \mathrm{mm}^{3}$ as a means of identifying patients at risk of infections, although not all patients who develop PCP have lymphopenia, therefore, precluding its use as an isolated risk identification guide $(24,43,65,75)$. Evaluating the utility of measuring CD4 counts in IBD patients on multiple immunosuppressants should be considered.

\section{CONCLUSION}

We described a case of severe PCP in an immunosuppressed lymphopenic pediatric IBD patient. This case reiterates the importance of limiting immunosuppression to its minimal effective dose. Although the incidence of PCP in the IBD population is low, it is an aggressive condition that has a higher relative risk in IBD patients compared to the general population. Moreover, it is associated with significant morbidity and mortality. PCP should be considered in the differential diagnosis of immunosuppressed pediatric IBD patients who develop respiratory symptoms, with a low threshold for treatment. Although there is no place for global PCP prophylaxis in IBD, in an era when there is increasing use of biologic agents

\section{REFERENCES}

1. Toruner M, Loftus EV Jr, Harmsen WS, Zinsmeister AR, Orenstein R, Sandborn WJ, et al. Risk factors for opportunistic infections in patients with inflammatory bowel disease. Gastroenterology (2008) 134(4):929-36. doi:10.1053/j.gastro.2008.01.012

2. Vanek J, Jirovec O. [Parasitic pneumonia. Interstitial plasma cell pneumonia of premature, caused by Pneumocystis carinii]. Zentralbl Bakteriol Parasitenkd Infektionskr Hyg (1952) 158(1-2):120-7.

3. Masur H, Michelis MA, Greene JB, Onorato I, Stouwe RA, Holzman RS, et al. An outbreak of community-acquired Pneumocystis carinii pneumonia: initial manifestation of cellular immune dysfunction. N Engl J Med (1981) 305(24):1431-8. doi:10.1056/NEJM198112103052402

4. Morris A, Norris KA. Colonization by Pneumocystis jirovecii and its role in disease. Clin Microbiol Rev (2012) 25(2):297-317. doi:10.1128/CMR.00013-12

5. Pyrgos V, Shoham S, Roilides E, Walsh TJ. Pneumocystis pneumonia in children. Paediatr Respir Rev (2009) 10(4):192-8. doi:10.1016/j.prrv.2009.06.010

6. Saltzman RW, Albin S, Russo P, Sullivan KE. Clinical conditions associated with PCP in children. Pediatr Pulmonol (2012) 47(5):510-6. doi:10.1002/ ppul.21577

7. Bienvenu AL, Traore K, Plekhanova I, Bouchrik M, Bossard C, Picot S. Pneumocystis pneumonia suspected cases in 604 non-HIV and HIV patients. Int J Infect Dis (2016) 46:11-7. doi:10.1016/j.ijid.2016.03.018

8. Desales AL, Mendez-Navarro J, Mendez-Tovar LJ, Ortiz-Olvera NX, Cullen G, Ocampo J, et al. Pneumocystosis in a patient with Crohn's disease treated with combination therapy with adalimumab. J Crohns Colitis (2012) 6(4):483-7. doi:10.1016/j.crohns.2011.10.012

9. Vargas S, Hughes WT, Santolaya ME, Ulloa AV, Ponce CA, Cabrera CE, et al. Search for primary infection by Pneumocystis carinii in a cohort of normal healthy infants. Clin Infect Dis (2001) 32(6):855-61. doi:10.1086/319340

10. Gigliotti F, Wright TW. Pneumocystis: where does it live? PLoS Pathog (2012) 8(11):e1003025. doi:10.1371/journal.ppat.1003025

11. Beck JM, Warnock ML, Curtis JL, Sniezek MJ, Arraj-Peffer SM, Kaltreider HB, et al. Inflammatory responses to Pneumocystis carinii in mice selectively depleted of helper T lymphocytes. Am J Respir Cell Mol Biol (1991) 5:186-97. doi:10.1165/ajrcmb/5.2.186

12. Limper AH, Martin WJ II. Pneumocystis carinii: inhibition of lung cell growth mediated by parasite attachment. J Clin Invest (1990) 85:391-6. doi:10.1172/ JCI114451 with combination immunosuppressive therapy, the risk-benefit profile of PCP prophylaxis should be revisited in selected cohorts such as patients on triple immunosuppression with corticosteroids, thiopurines, and a biological agent or calcineurin inhibitor especially in lymphopenic individuals. Further studies are required to guide definitive PCP prophylaxis in high risk subgroups of IBD patients.

\section{INFORMED CONSENT}

Written informed consent for publication of the case report and figures was obtained from the patient and parents.

\section{AUTHOR CONTRIBUTIONS}

SL performed the literature review and wrote the manuscript. MS and $\mathrm{KJ}$ critically reviewed the manuscript.

\section{ACKNOWLEDGMENTS}

The authors thank Dr. Oana Popescu for pathology slide images and Dr. Orlee Guttman for providing case information.

13. Kovacs JA, Hiemenz JW, Macher AM, Stover D, Murray HW, Shelhamer J, et al. Pneumocystis carinii pneumonia: a comparison between patients with the acquired immunodeficiency syndrome and patients with other immunodeficiencies. Ann Intern Med (1984) 100(5):663-71. doi:10.7326/0003-4819100-5-663

14. Fillatre P, Decaux O, Jouneau S, Revest M, Gacouin A, Robert-Gangneux F, et al. Incidence of Pneumocystis jiroveci pneumonia among groups at risk in HIV-negative patients. Am J Med (2014) 127(12):1242.e11-7. doi:10.1016/j. amjmed.2014.07.010

15. Monnet X, Vidal-Petiot E, Osman D, Hamzaoui O, Durrbach A, Goujard C, et al. Critical care management and outcome of severe Pneumocystis pneumonia in patients with and without HIV infection. Crit Care (2008) 12(1):R28. doi:10.1186/cc6806

16. Gruden JF, Huang L, Turner J, Webb WR, Merrifield C. High-resolution CT in the evaluation of clinically suspected Pneumocystis carinii pneumonia in AIDs patients with normal, equivocal or non specific radiographic findings. Am J Roentgenol (1997) 169:967-75. doi:10.2214/ajr.169.4.9308446

17. Limper AH, Offord KP, Smith TF, Martin WJ II. Pneumocystis carinii pneumonia. Differences in lung parasite number and inflammation in patients with and without AIDS. Am Rev Respir Dis (1989) 140(5):1204-9. doi:10.1164/ ajrccm/140.5.1204

18. Hviid CJ, Lund M, Sorensen A, Ellermann-Eriksen S, Jespersen B, Dam MY, et al. Detection of Pneumocystis jirovecii in oral wash from immunosuppressed patients as a diagnostic tool. PLoS One (2017) 12(3):e0174012. doi:10.1371/journal.pone.0174012

19. Flori P, Bellete B, Durand F, Raberin H, Cazorla C, Hafid J, et al. Comparison between real-time PCR, conventional PCR and different staining techniques for diagnosing Pneumocystis jiroveci pneumonia from bronchoalveolar lavage specimens. J Med Microbiol (2004) 53(Pt 7):603-7. doi:10.1099/ jmm.0.45528-0

20. Stern A, Green H, Paul M, Vidal L, Leibovici L. Prophylaxis for Pneumocystis pneumonia (PCP) in non-HIV immunocompromised patients. Cochrane Database Syst Rev (2014) 10:CD005590. doi:10.1002/14651858.CD005590. pub3

21. Smego R, Nagar S, Maloba B, Popara M. A meta-analysis of salvage therapy for Pneumocystis carinii pneumonia. Arch Intern Med (2001) 161:1529-33. doi:10.1001/archinte.161.12.1529

22. Hughes W, Leoung G, Kramer F. Comparison of atovaquone (566C80) with trimethoprim-sulfamethoxazole to treat Pneumocystis carinii 
pneumonia in patients with AIDS. N Engl J Med (1993) 328:1521-7. doi:10.1056/NEJM199305273282103

23. Pareja JG, Garland R, Koziel H. Use of adjunctive corticosteroids in severe adult non-HIV Pneumocystis carinii pneumonia. Chest (1998) 113(5):1215-24. doi:10.1378/chest.113.5.1215

24. Overgaard UM, Helweg-Larsen J. Pneumocystis jiroveci pneumonia (PCP) in HIV-1-negative patients: a retrospective study 2002-2004. Scand J Infect Dis (2007) 39(6-7):589-95. doi:10.1080/00365540601150497

25. Mansharamani NG, Garland R, Delaney D, Koziel H. Management and outcome patterns for adult Pneumocystis carinii pneumonia, 1985 to 1995. Chest (2000) 118(3):704-11. doi:10.1378/chest.118.3.704

26. Long MD, Farraye FA, Okafor PN, Martin C, Sandler RS, Kappelman MD. Increased risk of pneumocystis jiroveci pneumonia among patients with inflammatory bowel disease. Inflamm Bowel Dis (2013) 19(5):1018-24. doi:10.1097/MIB.0b013e3182802a9b

27. Cotter TG, Gathaiya N, Catania J, Loftus EV Jr, Tremaine WJ, Baddour LM, et al. Low risk of pneumonia from Pneumocystis jirovecii infection in patients with inflammatory bowel disease receiving immune suppression. Clin Gastroenterol Hepatol (2017) 15(6):850-6. doi:10.1016/j.cgh.2016.11.037

28. Tschudy J, Michail S. Disseminated histoplasmosis and Pneumocystis pneumonia in a child with Crohn disease receiving infliximab. J Pediatr Gastroenterol Nutr (2010) 51(2):221-2. doi:10.1097/MPG.0b013e3181c2c10d

29. Bernstein CN, Kolodny M, Block E, Shanahan F. Pneumocystis carinii pneumonia in patients with ulcerative colitis treated with corticosteroids. Am J Gastroenterol (1993) 88(4):574-7.

30. Khatchatourian M, Seaton TL. An unusual complication of immunosuppressive therapy in inflammatory bowel disease. Am J Gastroenterol (1997) 92(9):1558-60.

31. Scott AM, Myers GA, Harms BA. Pneumocystis carinii pneumonia postrestorative proctocolectomy for ulcerative colitis: a role for perioperative prophylaxis in the cyclosporine era? Report of a case and review of the literature. Dis Colon Rectum (1997) 40(8):973-6. doi:10.1007/BF02051208

32. Escher M, Stange EF, Herrlinger KR. Two cases of fatal Pneumocystis jirovecii pneumonia as a complication of tacrolimus therapy in ulcerative colitis a need for prophylaxis. JCrohns Colitis (2010) 4(5):606-9. doi:10.1016/j. crohns.2010.05.004

33. Kaur N, Mahl TC. Pneumocystis jiroveci (carinii) pneumonia after infliximab therapy: a review of 84 cases. Dig Dis Sci (2007) 52(6):1481-4. doi:10.1007/ s10620-006-9250-x

34. Howick J, Chalmers I, Glasziou P, Greenhalgh T, Heneghan C, Liberati A, et al. The Oxford 2011 Levels of Evidence (2011). Available from: http://www.cebm.net/index.aspx?o=5653

35. Lee JC, Bell DC, Guinness RM, Ahmad T. Pneumocystis jiroveci pneumonia and pneumomediastinum in an anti-TNF naive patient with ulcerative colitis. World J Gastroenterol (2009) 15:1897-900. doi:10.3748/wjg.15.1897

36. Takenaka R, Okada H, Mizuno M, Nasu J, Toshimori J, Tatsukawa M, et al. Pneumocystis carinii pneumonia in patients with ulcerative colitis. J Gastroenterol (2004) 39(11):1114-5. doi:10.1007/s00535-004-1454-2

37. Arts J, D’Haens G, Zeegers M, Van Assche G, Hiele M, D’Hoore A, et al. Long-term outcome of treatment with intravenous cyclosporin in patients with severe ulcerative colitis. Inflamm Bowel Dis (2004) 10(2):73-8. doi:10.1097/00054725-200403000-00002

38. Quan VA, Saunders BP, Hicks BH, Sladen GE. Cyclosporin treatment for ulcerative colitis complicated by fatal Pneumocystis carinii pneumonia. BMJ (1997) 314(7077):363-4. doi:10.1136/bmj.314.7077.363

39. Smith MB, Hanauer SB. Pneumocystis carinii pneumonia during cyclosporine therapy for ulcerative colitis. N Engl J Med (1992) 327(7):497-8. doi:10.1056/ NEJM199208133270714

40. Lawrance IC, Radford-Smith GL, Bampton PA, Andrews JM, Tan PK, Croft A, et al. Serious infections in patients with inflammatory bowel disease receiving anti-tumor-necrosis-factor-alpha therapy: an Australian and New Zealand experience. J Gastroenterol Hepatol (2010) 25(11):1732-8. doi:10.1111/j.1440-1746.2010.06407.x

41. Iwama T, Sakatani A, Fujiya M, Tanaka K, Fujibayashi S, Nomura Y, et al. Increased dosage of infliximab is a potential cause of Pneumocystis carinii pneumonia. Gut Pathog (2016) 8:2. doi:10.1186/s13099-016-0086-4

42. Velayos FS, Sandborn WJ. Pneumocystis carinii pneumonia during maintenance anti-tumor necrosis factor-alpha therapy with infliximab for Crohn's disease. Inflamm Bowel Dis (2004) 10(5):657-60. doi:10.1097/00054725200409000-00025
43. Kaur N, Mahl TC. Pneumocystis carinaii pneumonia associated with oral candidiasis after infliximab therapy for Crohn's disease. Dig Dis Sci (2004) 49:1458-60. doi:10.1023/B:DDAS.0000042246.58984.98

44. Stratakos G, Kalomenidis I, Papas V, Malagari K, Kollintza A, Roussos C, et al. Cough and fever in a female with Crohn's disease receiving infliximab. Eur Respir J (2005) 26(2):354-7. doi:10.1183/09031936.05.00005205

45. Estrada S, Garcia-Campos F, Calderon R, Delgado E, Bengoa R, Enciso C. Pneumocystis jiroveci (carinii) pneumonia following a second infusion of infliximab in a patient with ulcerative colitis. Inflamm Bowel Dis (2009) 15(2):315-6. doi:10.1002/ibd.20536

46. Sharma K, Rao P. Pneumocystis carinii pneumonia following infliximab infusion for Crohn disease. South Med J (2007) 100:331-3. doi:10.1097/ SMJ.0b013e31802fb3b4

47. Seddik M, Melliez H, Seguy D, Viget N, Cortot A, Colombel JF. Pneumocystis jiroveci (carinii) pneumonia after initiation of infliximab and azathioprine therapy in a patient with Crohn's disease. Inflamm Bowel Dis (2005) 11(6):618-20. Erratum in:Inflamm Bowel Dis (2005) 11(8):705. doi:10.1097/01. MIB.0000164002.32735.c2

48. Itaba S, Iwasa T, Sadamoto Y, Nasu T, Misawa T, Inoue K, et al. Pneumocystis pneumonia during combined therapy of infliximab, corticosteroid, and azathioprine in a patient with Crohn's disease. Dig Dis Sci (2007) 52(6):1438-41. doi:10.1007/s10620-006-9575-5

49. DeFilippis EM, Shaikh F, DeMauro A, Scherl EJ, Bosworth BP. Pneumocystis jiroveci pneumonia with recurrent pneumothorax requiring pleurodesis in inflammatory bowel disease. J Dig Dis (2015) 16(7):416-9. doi:10.1111/1751-2980.12257

50. Roblot F, Godet C, Le Moal G, Garo B, Faouzi Souala M, Dary M, et al. Analysis of underlying diseases and prognosis factors associated with Pneumocystis carinii pneumonia in immunocompromised HIV-negative patients. Eur J Clin Microbiol Infect Dis (2002) 21(7):523-31. doi:10.1007/s10096-002-0758-5

51. Yale SH, Limper AH. Pneumocystis carinii pneumonia in patients without acquired immunodeficiency syndrome: associated illness and prior corticosteroid therapy. Mayo Clin Proc (1996) 71(1):5-13. doi:10.4065/71.1.5

52. Okafor PN, Nunes DP, Farraye FA. Pneumocystis jiroveci pneumonia in inflammatory bowel disease: when should prophylaxis be considered? Inflamm Bowel Dis (2013) 19(8):1764-71. doi:10.1097/MIB.0b013e31828029f4

53. Poppers DM, Scherl EJ. Prophylaxis against Pneumocystis pneumonia in patients with inflammatory bowel disease: toward a standard of care. Inflamm Bowel Dis (2008) 14(1):106-13. doi:10.1002/ibd.20261

54. Friedman S. General principles of medical therapy of inflammatory bowel disease. Gastroenterol Clin North Am (2004) 33(2):191-208, viii. doi:10.1016/j. gtc.2004.02.003

55. Stenger AAME, Houtman PM, Bruyn GAW, Eggink HF, Pasma HR. Pneumocystis carinii pneumonia associated with low dose methotrexate treatment for rheumatoid arthritis. Scand J Rheumatol (2009) 23(1):51-3. doi:10.3109/03009749409102137

56. Watanabe K, Sakai R, Koike R, Sakai F, Sugiyama H, Tanaka M, et al. Clinical characteristics and risk factors for Pneumocystisjirovecii pneumonia in patients with rheumatoid arthritis receiving adalimumab: a retrospective review and case-control study of 17 patients. Mod Rheumatol (2013) 23(6):1085-93. doi:10.1007/s10165-012-0796-5

57. DeFilippis EM, Scherl EJ. Pneumocystis pneumonia in inflammatory bowel disease: the costs of immunosuppression. J Gastrointest Dig Syst (2015) 5:352. doi:10.4172/2161-069X.1000352

58. Komano Y, Harigai M, Koike R, Sugiyama H, Ogawa J, Saito K, et al. Pneumocystis jiroveci pneumonia in patients with rheumatoid arthritis treated with infliximab: a retrospective review and case-control study of 21 patients. Arthritis Rheum (2009) 61(3):305-12. doi:10.1002/art.24283

59. Colombel JF, Sandborn WJ, Panaccione R, Robinson AM, Lau W, Li J, et al. Adalimumab safety in global clinical trials of patients with Crohn's disease. Inflamm Bowel Dis (2009) 15(9):1308-19. doi:10.1002/ibd.20956

60. Takeuchi T, Tatsuki Y, Nogami Y, Ishiguro N, Tanaka Y, Yamanaka H, et al. Postmarketing surveillance of the safety profile of infliximab in 5000 Japanese patients with rheumatoid arthritis. Ann Rheum Dis (2008) 67(2):189-94. doi:10.1136/ard.2007.072967

61. Tai T. Pneumocystis carinii pneumonia following a second infusion of infliximab. Rheumatology (2002) 41:951-2. doi:10.1093/rheumatology/41.8.951

62. Grubbs JA, Baddley JW. Pneumocystis jirovecii pneumonia in patients receiving tumor-necrosis-factor-inhibitor therapy: implications for chemoprophylaxis. Curr Rheumatol Rep (2014) 16(10):445. doi:10.1007/s11926-014-0445-4 
63. Colombel JF, Sands BE, Rutgeerts P, Sandborn W, Danese S, D’Haens G, et al. The safety of vedolizumab for ulcerative colitis and Crohn's disease. Gut (2017) 66(5):839-51. doi:10.1136/gutjnl-2015-311079

64. Feagan BG, Sandborn WJ, Gasink C, Jacobstein D, Lang Y, Friedman JR, et al. Ustekinumab as induction and maintenance therapy for Crohn's disease. N Engl J Med (2016) 375(20):1946-60. doi:10.1056/NEJMoa1602773

65. Mansharamani NG, Balachandran D, Vernovsky I, Garland R, Koziel H. Peripheral blood CD4 + T-lymphocyte counts during Pneumocystis carinii pneumonia in immunocompromised patients without HIV infection. Chest (2000) 118(3):712-20. doi:10.1378/chest.118.3.712

66. Beukelman T, Xie F, Baddley JW, Chen L, Delzell E, Grijalva CG, et al. Brief report: incidence of selected opportunistic infections among children with juvenile idiopathic arthritis. Arthritis Rheum (2013) 65(5):1384-9. doi:10.1002/art.37866

67. Godeau B, Coutant-Perronne V, Le Thi Huong D, Guillevin L, Magadur G, De Bandt M, et al. Pneumocystis carinii pneumonia in the course of connective tissue disease: report of 34 cases. J Rheumatol (1994) 21(2):246-51.

68. Sepkowitz KA. Opportunistic infections in patients with and patients without acquired immunodeficiency syndrome. Clin Infect Dis (2002) 34:1098-107. doi:10.1086/339548

69. Okafor PN, Wasan SK, Farraye FA. Pneumocystis jiroveci pneumonia in patients with inflammatory bowel disease: a survey of prophylaxis patterns among gastroenterology providers. Inflamm Bowel Dis (2013) 19(4):812-7. doi:10.1097/MIB.0b013e31828029f4

70. Alhagamhmad MH, Day AS, Lemberg DA, Leach ST. An update of the role of nutritional therapy in the management of Crohn's disease. J Gastroenterol (2012) 47(8):872-82. doi:10.1007/s00535-012-0617-9

71. Sigall-Boneh R, Pfeffer-Gik T, Segal I, Zangen T, Boaz M, Levine A. Partial enteral nutrition with a Crohn's disease exclusion diet is effective for induction of remission in children and young adults with Crohn's disease. Inflamm Bowel Dis (2014) 20(8):1353-60. doi:10.1097/MIB.0000000000000110

72. Ruemmele FM, Veres G, Kolho KL, Griffiths A, Levine A, Escher JC, et al. Consensus guidelines of ECCO/ESPGHAN on the medical management of pediatric Crohn's disease. JCrohns Colitis (2014) 8(10):1179-207. doi:10.1016/j.crohns.2014.04.005

73. Okafor PN, Farraye FA, Okafor AT, Erim DO. Cost-effectiveness of prophylaxis against Pneumocystis jiroveci pneumonia in patients with Crohn's disease. Dig Dis Sci (2015) 60(12):3743-55. doi:10.1007/s10620-015-3796-4

74. Rahier JF, Magro F, Abreu C, Armuzzi A, Ben-Horin S, Chowers Y, et al. Second European evidence-based consensus on the prevention, diagnosis and management of opportunistic infections in inflammatory bowel disease. J Crohns Colitis (2014) 8(6):443-68. doi:10.1016/j.crohns.2013.12.013

75. Viget N, Vernier-Massouille G, Salmon-Ceron D, Yazdanpanah Y, Colombel JF. Opportunistic infections in patients with inflammatory bowel disease: prevention and diagnosis. Gut (2008) 57(4):549-58. doi:10.1136/ gut.2006.114660

Conflict of Interest Statement: The authors declare that the research was conducted in the absence of any commercial or financial relationships that could be construed as a potential conflict of interest.

Copyright (C) 2017 Lawrence, Sadarangani and Jacobson. This is an open-access article distributed under the terms of the Creative Commons Attribution License (CC BY). The use, distribution or reproduction in other forums is permitted, provided the original author(s) or licensor are credited and that the original publication in this journal is cited, in accordance with accepted academic practice. No use, distribution or reproduction is permitted which does not comply with these terms. 